Article

\title{
Exploring the Impact of Remoteness and Socio-Economic Status on Child and Adolescent Injury-Related Mortality in Australia
}

\author{
Amy E. Peden $1,2, *$ (D) and Richard C. Franklin ${ }^{2}$ (D) \\ 1 School of Population Health, UNSW Sydney, Kensington, NSW 2052, Australia \\ 2 College of Public Health, Medical and Veterinary Sciences, James Cook University, Townsville, \\ QLD 4811, Australia; richard.franklin@jcu.edu.au \\ * Correspondence: a.peden@unsw.edu.au
}

Citation: Peden, A.E.; Franklin, R.C. Exploring the Impact of Remoteness and Socio-Economic Status on Child and Adolescent Injury-Related Mortality in Australia. Children 2021, 8, 5. https://dx.doi.org/10.3390/ children8010005

Received: 26 November 2020 Accepted: 20 December 2020 Published: 24 December 2020

Publisher's Note: MDPI stays neutral with regard to jurisdictional claims in published maps and institutional affiliations.

Copyright: () 2020 by the authors. Licensee MDPI, Basel, Switzerland. This article is an open access article distributed under the terms and conditions of the Creative Commons Attribution (CC BY) license (https: / creativecommons.org/ licenses/by/4.0/).

\begin{abstract}
Injuries are a leading cause of harm for children. This study explores the impact of determinants of health on children (0-19 years) injury-related mortality (namely remoteness and socio-economic disadvantage, calculated using the index of relative socio-economic advantage and disadvantage (IRSAD)). Cause of death data from the Australian Bureau of Statistics were sourced for children in Australia between 1 July 2007 to 30 June 2017. Fifteen injury categories (ICD-10-AM external cause codes) were used. Burden and trends by injury mechanism were explored. A total of 5153 children died; with road traffic incidents (3.39 per 100,000 population), intentional self-harm (2.46) and drowning (0.72) being the leading mechanisms. Female fatality rates in very remote areas (8.73) were nine times higher than in major cities (Relative Risk $[R R]=8.73 ; 95 \%$ Confidence Interval [95\% CI]: 4.23-18.00). Fatality rates increased with remoteness; very remote areas recording an injury-related fatality rated six times $(\mathrm{RR}=5.84 ; 95 \% \mathrm{CI}$ : 3.76-9.12) that of major city residents. Accidental poisoning and intentional self-harm fatalities were more likely in high IRSAD areas, while road traffic fatalities were more likely in low and mid socio-economic areas $\left(X^{2}=69.1 ; p<0.001\right)$. People residing in regional and remote areas and from low socio-economic backgrounds already face significant health and lifestyle challenges associated with disadvantage. It is time to invest in injury prevention interventions for these populations, as well as upstream policy strategies to minimize any further preventable loss of life.
\end{abstract}

Keywords: injury; child; adolescent; risk factor; rurality; socio-economic; determinants of health; road traffic injury; falls; poisoning; drowning; violence; self-harm; prevention; intervention; epidemiology

\section{Introduction}

Globally, injuries are a leading cause of mortality and morbidity for children and adolescents. In 2017, the Global Burden of Disease study estimated 4.48 million injury deaths globally, an increase of 5.3\% since 1990 [1]. However, some progress is being made in reducing injury-related deaths, with both years of life lost and age-standardized mortality rates decreasing between 1990 and 2017 [1]. Injury-related morbidity is also a significant global concern. New cases of non-fatal injury are increasing, with 520 million cases recorded globally in 2017, while years lived with a disability also increased [1].

Understanding and preventing injuries is complex as they may be intentional or unintentional, be due to a range of mechanisms such as road transport, falls, drowning, burns, poisoning, interpersonal violence and suicide, impact all ages and require a range of strategies to prevent them from occurring [1-4]. As the risk factors and prevention strategies needed to address unintentional and intentional injuries often differ, there is a need for studies which explore the causes of injury by age groups.

Injury risk is impacted by external factors including determinants of health. Determinants of health, referred to as the causes of the causes [5], are the conditions in which people are born, grow, live, work and play which impact health [6]. Determinants which impact 
health, including injury risk, include socio-economic conditions, daily living conditions, education levels and individual health-related factors [7,8]. Addressing the determinants of health helps to prevent events from occurring [5]. Strategies to prevent injuries need to be designed to address injury risk using a range of strategies from downstream (individual level) to upstream (system level), otherwise they are likely to be ineffective, especially when used in isolation, and must address underlying determinants of health [9].

Geographical remoteness and socio-economic status are determinants which impact health, including injury $[10,11]$. Poorer health outcomes are seen in rural dwelling populations, with greater hospitalization rates and disease burden [12,13]. This increased injury risk in rural locations also goes hand in hand with socio-economic disadvantage [14], which has been identified as a factor impacting injury risk [15-18]. Effective injury prevention strategies must consider these (and other) determinants of health when identifying areas of need and designing interventions.

Children and adolescents experience significant fatal and non-fatal burden due to injuries [19] and are particularly vulnerable to harm due to drowning [2,20], falls [3,21] and road traffic injuries $[4,22]$. Reducing injury-related mortality and morbidity is vital in order for nations to meet child and adolescent health targets within the Sustainable Development Goals [23,24]. Reducing injury-related harm among children and adolescents represents the area where the greatest health gains can be made [25].

While fatal child injury rates are declining, there are clear variations based on socioeconomic inequalities [26]. Therefore, within an Australian context, this study aims to explore injury-related mortality among children and adolescents to identify the impact of determinants of health, specifically rurality and a composite measure of socio-economic advantage and disadvantage (Index of Relative Socio-economic Advantage and Disadvantage (IRSAD)) of residential location, with an aim to inform future prevention efforts.

\section{Materials and Methods}

This study reports a total population analysis of injury-related mortality among children and adolescents aged 0-19 years (henceforth referred to as children) in Australia between 1 January 2007 and 30 June 2017 (a period of 10 years), with a particular focus on determinants of health - namely remoteness and IRSAD of the child's residential location.

\subsection{Data Source}

Cause of Death Unit Record File data were sourced from the Australian Bureau of Statistics (ABS). Data are provided to approved applicants only, but similar publicly available data to the Cause of Death data release collated by the ABS annually are provided [27]. Variables made available for analysis were date of death, sex, age group, jurisdiction of death (Australian state or territory and statistical local area), International Classification of Disease (ICD)-10 cause of death code and statistical local area. A statistical local area is a geographical area as used by the ABS. This study specifically uses statistical area level 2 which represents a community that interacts together socially and economically [28].

\subsection{Case Identification and Data Cleaning}

All deaths that had a primary cause of death injury ICD-10-AM [29] code were selected; only cases where the incident occurred during the study period were included, people who were aged less than 20 years were included and those who resided in Australia (i.e., visitors to Australia were excluded). Prior to commencing data coding and analysis, a total of 75 cases were removed; being 54 overseas residents and 21 with unknown residence.

This study examines injury-related deaths that were registered and who died between 1 January 2007 and 31 December 2017; noting that particularly for 2017, this would represent an approximate under-numeration of $6 \%$ (this proportion is based on the proportion of people who died within a given year but whose death was not registered until the following year). This particularly impacts those deaths which occur later in the year 
i.e., November and December. As such, trends over time are explored on Australian financial years 1 July to 30 June, from 1 July 2007 to 30 June 2017.

\subsection{Coding of Injury Mechanisms}

Fifteen categories of injury mechanism were collated using the ICD-10 codes. Due to small numbers of cases, the mechanisms of 'overexertion, strenuous and repetitive movements' (X50) and 'contact with venomous animals and plants' (X20-29) were grouped into 'Other'. The coding structure for the categories is described in Table 1.

Table 1. Injury categories used in study and associated International Classification of Diseases (ICD)-10 codes.

\begin{tabular}{|c|c|c|}
\hline $\begin{array}{l}\text { Injury Mechanisms } \\
\text { Category. }\end{array}$ & ICD-10 Code & Code Explanation \\
\hline \multirow{9}{*}{$\begin{array}{l}\text { Road traffic and other } \\
\text { land transport }\end{array}$} & V00-V09 & Pedestrian injured in transport accident \\
\hline & V10-V19 & Pedal cycle rider injured in transport accident \\
\hline & V20-V29 & Motorcycle rider injured in transport accident \\
\hline & V30-V39 & Occupant of three-wheeled motor vehicle injured in transport accident \\
\hline & V40-V49 & Car occupant injured in transport accident \\
\hline & V50-V59 & Occupant of pick-up truck or van injured in transport accident \\
\hline & V60-V69 & Occupant of heavy transport vehicle injured in transport accident \\
\hline & V70-79 & Bus occupant injured in transport accident \\
\hline & V80-89 & Other land transport accidents \\
\hline \multirow{3}{*}{$\begin{array}{l}\text { Water transport, air and } \\
\text { space transport and } \\
\text { other/unspecified }\end{array}$} & V90-94 & Water transport accidents \\
\hline & V95-V97 & Air and space transport accidents \\
\hline & V98-V99 & Other and unspecified transport accidents \\
\hline Falls & W00-W19 & Slipping, tripping, stumbling and falls \\
\hline \multirow{2}{*}{$\begin{array}{l}\text { Exposure to } \\
\text { mechanical forces }\end{array}$} & W20-W49 & Exposure to inanimate mechanical forces \\
\hline & W50-W64 & Exposure to animate mechanical forces \\
\hline Drowning & W65-74 & Accidental non-transport drowning and submersion \\
\hline $\begin{array}{l}\text { Other accidental threats } \\
\text { to breathing }\end{array}$ & W75-W84 & Other accidental threats to breathing \\
\hline $\begin{array}{l}\text { Electrocution, radiation } \\
\text { and extreme } \\
\text { temperature }\end{array}$ & W85-W99 & $\begin{array}{l}\text { Exposure to electrical current, radiation and extreme ambient air } \\
\text { temperature and pressure }\end{array}$ \\
\hline \multirow{2}{*}{ Burns } & X00-X09 & Exposure to smoke, fire and flames \\
\hline & X10-X19 & Contact with heat and hot substances \\
\hline Forces of nature & X30-X39 & Exposure to forces of nature \\
\hline Accidental poisoning & X40-X49 & Accidental poisoning by and exposure to noxious substances \\
\hline $\begin{array}{l}\text { Accidental exposure to } \\
\text { other forces }\end{array}$ & X51-X59 & Accidental exposure to other specified factors \\
\hline Intentional self-harm & $\mathrm{X} 60-\mathrm{X} 84$ & Intentional self-harm \\
\hline Assault & X85-Y09 & Assault \\
\hline Undetermined intent & Y10-Y34 & Event of undetermined intent \\
\hline \multirow{5}{*}{ Other } & X20-X29 & Contact with venomous animals and plants \\
\hline & X50 & Overexertion and strenuous or repetitive movements \\
\hline & Y35 & Legal intervention and operations of war \\
\hline & Y40-Y84 & Complications of medical and surgical care \\
\hline & Y85-Y89 & Sequelae of external causes of morbidity and mortality \\
\hline
\end{tabular}




\subsection{Coding of Determinants of Health}

The impact of determinants of health on child injury risk was explored by remoteness and IRSAD. The remoteness of the child's residential location was calculated by matching the nine digit statistical local area (SLA) code to the corresponding Australian Standard Geographical Classification (ASGC) category (i.e., major cities, inner regional, outer regional, remote and very remote) [30].

The nine-digit SLA was also used to code the victim's residential location to the corresponding decile on the index of socio-economic advantage and disadvantage (IRSAD). IRSAD aligns the statistical local area with a decile ranking (1-10), with areas ranked 1 being the most disadvantaged. Victims' residential postcode current IRSAD was used as a proxy for their familial socio-economic status [31]. IRSAD includes 17 measures around: income, education, employment, car ownership, internet connection, disability, family structure and renting status [32], which are combined to produce 10 IRSAD deciles. The IRSAD deciles were coded to low (deciles 1-3), mid (deciles 4-7) and high (deciles 8-10) for ease of analysis. Data between 2006 and 2011 were coded to the socio-economic indexes for areas (SEIFA) classification in 2011 and data between 2012 and 2017 were coded to SEIFA 2016 [33].

\subsection{Statistical Analysis}

Temporal trends over time in fatal injury mechanism were explored using the linear calculation in Microsoft Excel 365 (Build: 13426.20274). Crude rates and relative risk (RR) with a $95 \%$ confidence interval (CI) were used to calculate the impact of remoteness of residential location on injury-related fatalities. Crude rates per 100,000 population were calculated for all children $0-19$ years, by sex and by age group (i.e., $0-4$ years, 5-9 years, 10-14 years and 15-19 years), using the population from June of each year [34]. Population data by ASGC classification are currently only available for years in which the national census has been conducted. Therefore, a two-year average for the population was calculated using census years (2011 [35] and 2016 [36]) and this was used with a 10-year average of the deaths to calculate crude annualized injury-related fatality rates for children per 100,000 population by ASGC remoteness classification. Rates were used to calculate relative risk (using a MedCalc calculator [37]), with a 95\% confidence interval using the lowest rate as the control group.

Univariate and chi-square analyses (calculated in International Business Machines [IBM] Corporation Statistical Package for the Social Sciences [SPSS] V25 [38]) were used to explore the impact of IRSAD on injury-related fatalities. Population data by grouped IRSAD decile (low, mid, and high) and age group are not publicly available in Australia. Therefore, the proportional of the all-age population in Australia as at 2016 by grouped IRSAD decile was calculated and assumed to hold true for children aged 0-19 years across the study period. These proportions were used to calculate non-parametric chi-square tests of significance. A modified Bonferonni correction, as suggested by Keppel [39], was applied at the 0.05 level, where multiple categories within a variable have been analyzed.

\subsection{Ethics Approval}

This study received ethics approval from the James Cook University Human Research Ethics Committee (H6136). Due to ethical constraints associated with reporting small numbers, small cell counts less than five (and their associated percentages) are reported as not presented (NP).

\section{Results}

Across the study period, there were a total of 5153 children who died due to fatal injuries. As a rate per 100,000 population, injury-related mortality among 0-19-year-olds in Australia varied from a high of 10.80 in 2008-09 to a low of 7.26 in 2013-14. The temporal trend across the study period shows a decline $\left(y=-0.3166 x+10.627 ; R^{2}=0.72\right)$ (Figure 1). 


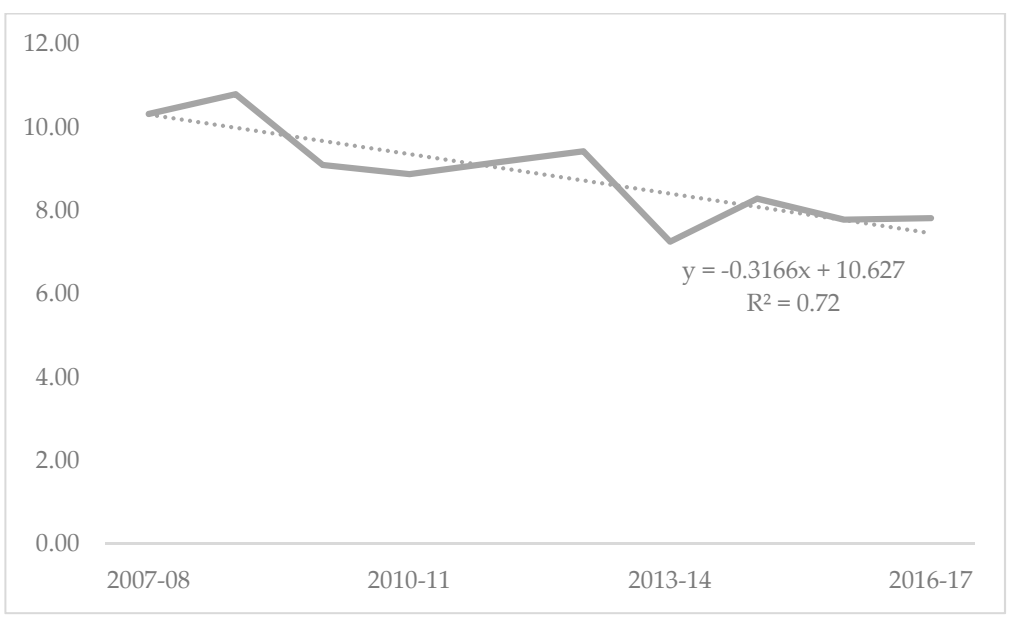

Figure 1. Crude rate per 100,000 of injury-related fatalities among children and adolescents 0-19 years, Australia 2007-08 to 2016-17.

The highest rates of fatal injury were seen in the 15-19 years age group with an average rate across the study period of 22.23 per 100,000, compared with the lowest rate of 2.63 per 100,000 among the 5-9 years age group. Crude injury-fatality rates are declining among 15-19-year-olds, with stagnant rates among 0-4-year-olds and 5-9-year-olds, with a slight upturn in rates among 10-14-year-olds (Figure 2).

Males accounted for $67.7 \%$ of all fatalities $(n=3487)$. Males were overrepresented in all age groups, rising from $59.1 \%$ of all injury-related fatalities in the $0-4$ years age group, to $71.8 \%$ of all fatalities in the $15-19$ years age group.

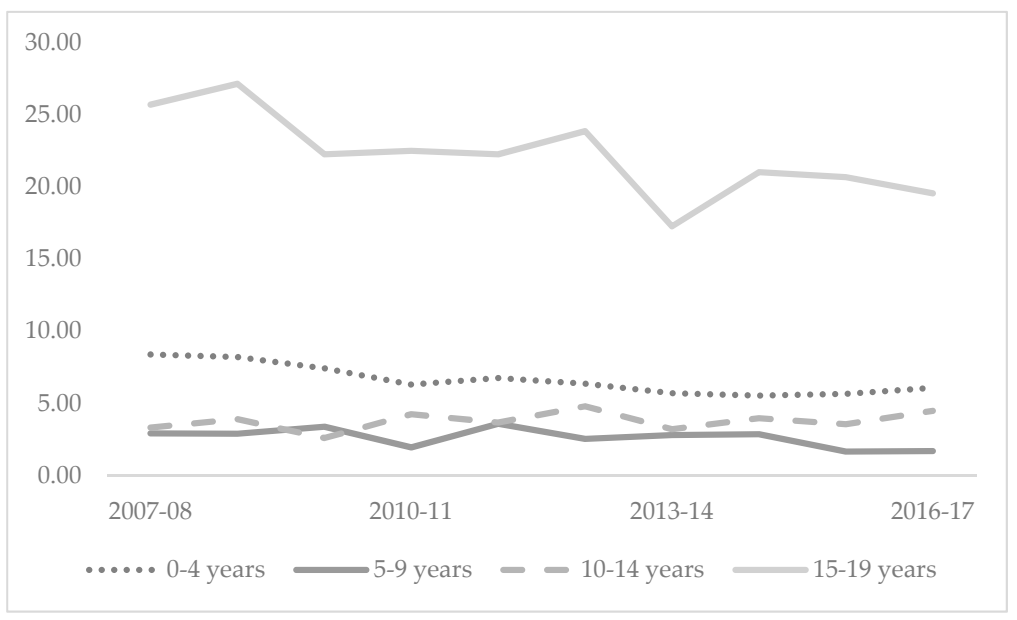

Figure 2. Crude rate per 100,000 of injury-related fatalities among children and adolescents 0-19 years, Australia 2007-08 to 2016-17.

Road traffic and other land transport incidents was the leading injury mechanism, accounting for $38.2 \%(n=1970)$ of the overall injury-related fatality burden, followed by intentional self-harm $(n=1432 ; 27.8 \%)$ and drowning $(n=419 ; 8.1 \%)$. The overrepresentation of males was most pronounced in injury-related fatalities as a result of falls $(82.6 \%$ male) and electrocution, radiation and extreme temperatures ( $80.0 \%$ male). When calculated as crude fatality rates, road traffic and other land transport incidents recorded a fatality rate of 3.39 per 100,000 population, compared to 2.46 for intentional self-harm and $0.72 / 100,000$ population for drowning (Table 2). 
Table 2. Incidence of injury-related fatality by mechanism, proportion of total and crude rate per 100,000 population among children and adolescents 0-19 years of age, Australia, 2007-08-2016-17.

\begin{tabular}{|c|c|c|c|}
\hline Injury Mechanism & Incidence $(n=)$ & $\begin{array}{l}\text { Proportion of } \\
\text { Total }(\%)\end{array}$ & $\begin{array}{c}\text { Crude Rate/100,000 } \\
\text { Population }\end{array}$ \\
\hline Total & 5153 & 100.0 & 8.86 \\
\hline Road traffic and other land transport & 1970 & 38.2 & 3.39 \\
\hline Water transport, air and space transport and other/unspecified & 39 & 0.8 & 0.07 \\
\hline 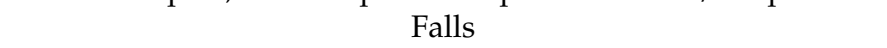 & 92 & 1.8 & 0.16 \\
\hline Exposure to mechanical forces & 125 & 2.4 & 0.21 \\
\hline Drowning & 419 & 8.1 & 0.72 \\
\hline Electrocution, radiation and extreme temperatures & 15 & 0.3 & 0.03 \\
\hline Burns & 112 & 2.2 & 0.19 \\
\hline Forces of nature & 35 & 0.7 & 0.06 \\
\hline Accidental poisoning & 167 & 3.2 & 0.29 \\
\hline Accidental exposure to other forces & 39 & 0.8 & 0.07 \\
\hline Intentional self-harm & 1432 & 27.8 & 2.46 \\
\hline Assault & 292 & 5.7 & 0.50 \\
\hline Undetermined intent & 144 & 2.8 & 0.25 \\
\hline Other accidental threats to breathing & 228 & 4.4 & 0.39 \\
\hline Other & 44 & 0.9 & 0.08 \\
\hline
\end{tabular}

\subsection{Impact of Social Determinants on Injury-Related Fatalities-Remoteness Classification}

The rate of injury-related fatalities increased as remoteness increased. Major cities record a crude rate of 6.64 injury-related fatalities per 100,000 residents; rising to a rate of 38.90 per 100,000 residents in very remote areas. Very remote areas recorded injury-related fatalities at six times $(\mathrm{RR}=5.84 ; \mathrm{CI}$ : 3.76-9.12) the rate of major city residents (Table 3).

Table 3. Crude rate of injury-related fatality by remoteness classification, relative risk with $95 \%$ confidence interval, children and adolescents 0-19 years of age, Australia, 2007-08-2016-17.

\begin{tabular}{cccc}
\hline $\begin{array}{c}\text { Remoteness } \\
\text { Classification }\end{array}$ & $\begin{array}{c}\text { Proportional } \\
\text { Population } \\
\text { Distribution (\%) }\end{array}$ & $\begin{array}{c}\text { Crude Rate of } \\
\text { Injury-Related } \\
\text { Fatality/100,000 } \\
\text { Population }\end{array}$ & $\begin{array}{c}\text { Relative Risk (95\% } \\
\text { Confidence Interval) }\end{array}$ \\
\hline Major Cities & 69.9 & 6.64 & 1 \\
Inner Regional & 18.8 & 12.48 & $1.88(1.52-2.31)$ \\
Outer Regional & 9.0 & 15.41 & $2.32(1.80-2.98)$ \\
Remote & 1.4 & 25.75 & $3.88(2.46-6.10)$ \\
Very Remote & 1.0 & 38.90 & $5.86(3.76-9.12)$ \\
\hline
\end{tabular}

Males recorded higher rates of fatal injury than females across all remoteness classifications, with the highest rates seen in very remote areas (12.52 for males compared to 9.79 for females). When compared to major cities, the relative risk of an injury-related fatality was six higher in very remote areas for males $(R R=5.62 ; C I$ : 3.20-9.87) and nine times higher for females ( $R R=8.73$; $C I$ : 4.23-18.00). Rates of injury-related fatalities were highest for 15-19-year-olds across all remoteness classification, ranging from 17.11 fatalities per 100,000 residents in major cities, to a rate of 102.33 in very remote areas (Table 4).

Across the five remoteness classification categories, road traffic and other land transport incidents (2.45) and intentional self-harm (2.12) recorded the highest rates of fatal injury in areas classified as major cities. This pattern continued across all remoteness classifications, with the exception of very remote areas, where the rate of injury-related fatalities associated with intentional self-harm (16.97) overtook that of road traffic and other land transport (14.39). The highest RR of injury-related fatality was for electrocution, radiation and extreme temperatures, with an 18 times ( $R R=18.24$; CI: 0.02-18638.89) higher risk of dying from this injury mechanism in a very remote area than in a major city. (Table 5). 


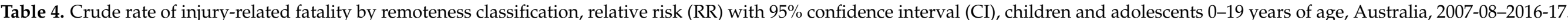

\begin{tabular}{|c|c|c|c|c|c|c|c|c|c|c|}
\hline \multicolumn{11}{|c|}{ Crude Rate of Injury-Related Fatality/100,000 Population } \\
\hline & $\begin{array}{l}\text { Major } \\
\text { Cities }\end{array}$ & $\begin{array}{c}\text { RR }(95 \% \\
\text { CI) }\end{array}$ & $\begin{array}{c}\text { Inner } \\
\text { Regional }\end{array}$ & RR $(95 \%$ CI) & $\begin{array}{c}\text { Outer } \\
\text { Regional }\end{array}$ & RR $(95 \%$ CI $)$ & Remote & RR $(95 \%$ CI) & $\begin{array}{c}\text { Very } \\
\text { Remote }\end{array}$ & RR $(95 \%$ CI) \\
\hline \multicolumn{11}{|c|}{ Sex } \\
\hline Male & 2.27 & 1 & 4.53 & $2.00(1.55-2.57)$ & 5.37 & $2.39(1.76-3.24)$ & 9.16 & $4.04(2.35-6.97)$ & 12.52 & $5.62(3.20-9.87)$ \\
\hline Female & 1.08 & 1 & 1.93 & $1.77(1.22-2.57)$ & 2.58 & $2.36(1.51-3.68)$ & 4.40 & $4.00(1.75-9.16)$ & 9.79 & $8.73(4.23-18.00)$ \\
\hline \multicolumn{11}{|c|}{ Age Group } \\
\hline $0-4$ years & 4.94 & 1 & 8.80 & $1.78(1.08-2.93)$ & 14.65 & $2.97(1.74-5.06)$ & 18.23 & $3.69(1.33-10.21)$ & 24.43 & $4.94(1.72-14.20)$ \\
\hline 5-9 years & 1.63 & 1 & 4.11 & $2.53(1.17-5.44)$ & 5.11 & $3.15(1.28-7.74)$ & 9.95 & $6.12(1.45-25.77)$ & 12.49 & $7.68(1.71-34.55)$ \\
\hline 15-19 years & 17.11 & 1 & 32.31 & $1.89(1.46-2.45)$ & 37.48 & $2.19(1.58-3.03)$ & 71.63 & $4.18(2.29-7.64)$ & 102.33 & $5.97(3.28-10.88)$ \\
\hline
\end{tabular}




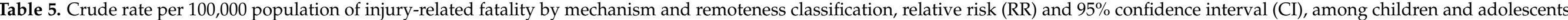
0-19 years of age, Australia, 2007-08-2016-17.

\begin{tabular}{|c|c|c|c|c|c|c|c|c|c|c|}
\hline \multirow[b]{2}{*}{ Injury Mechanism } & \multicolumn{10}{|c|}{ Crude Rate of Injury-Related Fatality/100,000 Population } \\
\hline & $\begin{array}{l}\text { Major } \\
\text { Cities }\end{array}$ & $\begin{array}{c}\text { RR } \\
(95 \% \text { CI })\end{array}$ & $\begin{array}{c}\text { Inner } \\
\text { Regional }\end{array}$ & RR $(95 \%$ CI $)$ & $\begin{array}{c}\text { Outer } \\
\text { Regional }\end{array}$ & RR $(95 \%$ CI $)$ & Remote & RR $(95 \%$ CI $)$ & $\begin{array}{c}\text { Very } \\
\text { Remote }\end{array}$ & RR $(95 \%$ CI $)$ \\
\hline $\begin{array}{l}\text { Road traffic and other } \\
\text { land transport }\end{array}$ & 2.45 & 1 & 6.24 & $\begin{array}{c}2.55 \\
(1.86-3.48)\end{array}$ & 7.37 & $\begin{array}{c}3.01 \\
(2.06-4.38)\end{array}$ & 10.77 & 4.39 (2.17-8.89) & 14.39 & $5.87(2.83-12.18)$ \\
\hline $\begin{array}{l}\text { Water transport, air and space } \\
\text { transport and other/unspecified }\end{array}$ & 0.06 & 1 & 0.08 & $\begin{array}{c}1.34 \\
(0.12-14.92)\end{array}$ & 0.16 & $\begin{array}{c}2.47 \\
(0.20-30.66)\end{array}$ & 0.26 & $\begin{array}{c}4.05 \\
(0.04-385.50)\end{array}$ & 0.18 & $2.92(0.01-1622.28)$ \\
\hline Falls & 0.15 & 1 & 0.18 & $\begin{array}{c}1.20 \\
(0.23-6.15)\end{array}$ & 0.25 & $\begin{array}{c}1.70 \\
(0.25-11.37)\end{array}$ & 0.64 & $4.30(0.24-77.05)$ & 0.37 & $2.47(0.03-213.07)$ \\
\hline Drowning & 0.64 & 1 & 1.05 & $\begin{array}{c}1.65 \\
(0.82-3.35)\end{array}$ & 1.45 & $\begin{array}{c}2.27 \\
(1.00-5.15)\end{array}$ & 1.41 & $2.21(0.33-14.93)$ & 2.58 & $4.05(0.74-22.22)$ \\
\hline $\begin{array}{l}\text { Electrocution, radiation and } \\
\text { extreme temperatures }\end{array}$ & 0.01 & 1 & 0.06 & $\begin{array}{c}5.59 \\
(0.10-305.20)\end{array}$ & 0.04 & $\begin{array}{c}3.86 \\
(0.02-828.20)\end{array}$ & 0.26 & $\begin{array}{c}25.34 \\
(0.12-5432.68)\end{array}$ & 0.18 & $\begin{array}{c}18.24 \\
(0.02-18638.89)\end{array}$ \\
\hline Burns & 0.14 & 1 & 0.40 & $\begin{array}{c}2.79 \\
(0.79-9.90)\end{array}$ & 0.25 & $\begin{array}{c}1.79 \\
(0.27-12.09)\end{array}$ & 0.26 & $\begin{array}{c}1.81 \\
(0.02-156.60)\end{array}$ & 0.92 & $6.51(0.36-117.53)$ \\
\hline Forces of nature & 0.05 & 1 & 0.10 & $\begin{array}{c}1.95 \\
(0.19-19.59)\end{array}$ & 0.10 & $\begin{array}{c}3.68 \\
(0.34-39.81)\end{array}$ & 0.13 & $\begin{array}{c}2.41 \\
(0.00-1373.41)\end{array}$ & 0.18 & $3.47(0.01-1976.44)$ \\
\hline Accidental exposure to other forces & 0.08 & 1 & 0.08 & $\begin{array}{c}1.08 \\
(0.10-11.30)\end{array}$ & 0.06 & $\begin{array}{c}0.75 \\
(0.02-31.72)\end{array}$ & 0.13 & $\begin{array}{c}1.64 \\
(0.00-887.94)\end{array}$ & 0.37 & $4.71(0.05-432.97)$ \\
\hline Intentional self-harm & 2.12 & 1 & 3.22 & $\begin{array}{c}1.52 \\
(1.02-2.26)\end{array}$ & 4.32 & $\begin{array}{c}2.04 \\
(1.28-3.26)\end{array}$ & 7.69 & $3.63(1.59-8.32)$ & 16.97 & $8.02(4.06-15.84)$ \\
\hline Assault & 0.50 & 1 & 0.41 & $\begin{array}{c}0.83 \\
(0.30-2.34)\end{array}$ & 0.96 & $\begin{array}{c}1.92 \\
(0.71-5.17)\end{array}$ & 1.03 & $2.06(0.22-19.25)$ & 1.11 & $2.22(0.17-28.99)$ \\
\hline Undetermined intent & 0.20 & 1 & 0.51 & $\begin{array}{c}2.58 \\
(0.86-7.72)\end{array}$ & 0.43 & $\begin{array}{c}2.18 \\
(0.49-9.73)\end{array}$ & 0.38 & $1.95(0.05-74.75)$ & 0.55 & $2.81(0.07-107.57)$ \\
\hline $\begin{array}{l}\text { Other accidental threats to } \\
\text { breathing }\end{array}$ & 0.34 & 1 & 0.47 & $\begin{array}{c}1.40 \\
(0.50-3.91)\end{array}$ & 0.72 & $\begin{array}{c}2.15 \\
(0.68-6.80)\end{array}$ & 1.92 & $5.72(1.06-30.92)$ & 1.29 & $3.84(0.35-42.47)$ \\
\hline Other & 0.07 & 1 & 0.10 & $\begin{array}{c}1.41 \\
(0.71-2.83)\end{array}$ & 0.18 & $\begin{array}{c}2.40 \\
(1.14-5.07)\end{array}$ & 0.26 & $3.50(0.83-14.65)$ & 0.00 & UTBC \\
\hline
\end{tabular}


When compared to females, a proportionately higher number of males in the 0-4 years age group died from road transport and other land transport injuries in major cities (57.1\%), rising to $79.3 \%$ for the $15-19$ years age group in very remote areas. When compared to males, a proportionately higher number of females aged 10-14 years died due to road transport related injuries in very remote areas (62.5\%). For intentional self-harm related fatalities, sex differences were most pronounced among 15-19-year-olds in inner regional areas, where males accounted for $73.1 \%$ of fatalities. Sex differences for drowning were most pronounced in major cities for the 15-19 years age group, with males accounting for $90.9 \%$ of all drowning-related fatalities.

\subsection{Impact of Social Determinants on Injury-Related Fatalities-Socio-Economic Classification}

There was an annual average of 214 injury-related fatalities in areas classified as mid IRSAD decile, followed by 204 fatalities for low IRSAD decile residences. High IRSAD deciles recorded the lowest average, with 97 injury-related fatalities annually. Injury-related fatalities declined in all three IRSAD decile classifications across the study period, with the largest decrease occurring in the mid decile $\left(y=-9.1273 x+264.4 ; R^{2}=0.6734\right)$. (Figure 3 ).

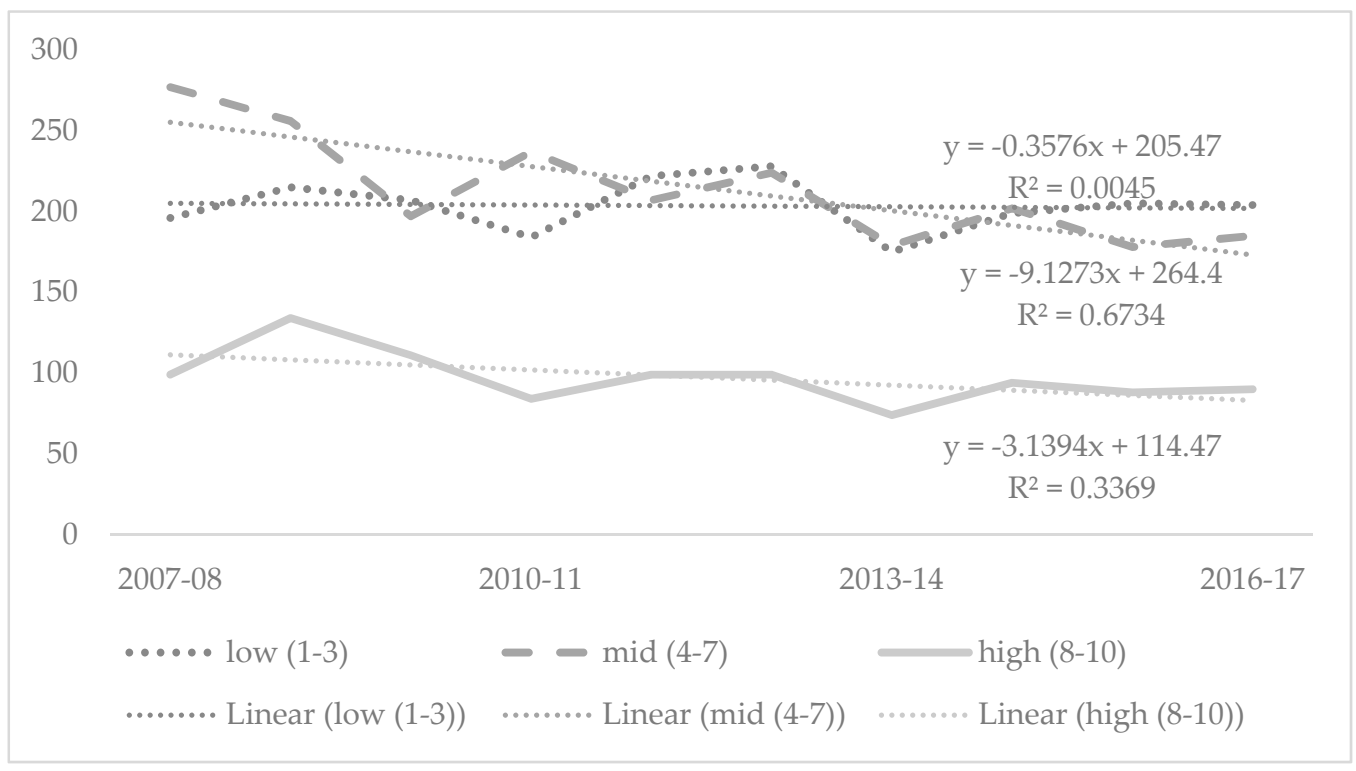

Figure 3. Injury-related fatalities among children and adolescents 0-19 years by index of relative socio-economic advantage and disadvantage (IRSAD) decile, Australia 2007-08 to 2016-17. Note: there were four cases with unknown IRSAD.

The highest proportion of injury-related fatalities occurred in areas classified as being mid IRSAD deciles (41.6\%) and among males (67.7\%). Males accounted for a higher proportion of injury-related fatalities than females across all IRSAD deciles. A higher proportion of female injury-related fatalities occurred among high IRSAD deciles $(20.0 \%)$ than males $(18.4 \%)$, however sex by IRSAD decile did not have a statistically significant impact on injury-related fatalities $\left(X^{2}=1.86 ; p=0.395\right)$. (Table 6) 
Table 6. Injury-related fatalities by sex and index of relative socio-economic advantage and disadvantage decile (IRSAD), Australia, 2007-08 to 2016-17.

\begin{tabular}{|c|c|c|c|c|c|c|c|c|c|}
\hline \multirow{3}{*}{ Sex } & \multicolumn{8}{|c|}{ IRSAD Decile } & \multirow{3}{*}{$\mathrm{X}^{2}(p$ Value $)$} \\
\hline & \multicolumn{2}{|c|}{ Total } & \multicolumn{2}{|c|}{ Low (Deciles 1-3) } & \multicolumn{2}{|c|}{ Mid (Deciles 4-7) } & \multicolumn{2}{|c|}{ High (Deciles 8-10) } & \\
\hline & $N$ & $\%$ & $N$ & $\%$ & $N$ & $\%$ & $N$ & $\%$ & \\
\hline Total & 5149 & 100.0 & 2035 & 39.5 & 2142 & 41.6 & 972 & 18.9 & \\
\hline Male & 3485 & 67.7 & 1387 & 39.8 & 1458 & 41.8 & 640 & 18.4 & $1857(n-0395)$ \\
\hline Female & 1664 & 32.3 & 648 & 38.9 & 684 & 41.1 & 332 & 20.0 & $1.037(p=0.393)$ \\
\hline
\end{tabular}

Note: excludes four cases with unknown IRSAD classification.

Across all age groups, the highest proportion of injury-related fatalities occurred in areas classified as low IRSAD, with the exception of the 15-19 years age group, where the highest proportion occurred in areas classified as mid IRSAD (36.9\%). There was a statistically significant difference in injury-related fatalities for age group by IRSAD. Older children (15-19-year-olds) were more likely to die from injury-related incidents in areas classified as high IRSAD, whereas children ( $0-4$ years) were more likely to die from injury-related incidents if residing in low IRSAD areas $\left(X^{2}=28.58 ; p<0.001\right)$ (Table 7).

Table 7. Injury-related fatalities by age group and index of relative socio-economic advantage and disadvantage decile (IRSAD), Australia, 2007/08 to 2016/17.

\begin{tabular}{|c|c|c|c|c|c|c|c|c|c|}
\hline \multirow{3}{*}{$\begin{array}{l}\text { Age Group of } \\
\text { Injury-Related } \\
\text { Fatalities }\end{array}$} & \multicolumn{8}{|c|}{ IRSAD Decile } & \multirow{3}{*}{$\mathrm{X}^{2}$ ( $p$ Value $)$} \\
\hline & \multicolumn{2}{|c|}{ Total } & \multicolumn{2}{|c|}{$\begin{array}{c}\text { Low (Deciles } \\
1-3)\end{array}$} & \multicolumn{2}{|c|}{$\begin{array}{c}\text { Mid (Deciles } \\
4-7)\end{array}$} & \multicolumn{2}{|c|}{$\begin{array}{c}\text { High (Deciles } \\
8-10)\end{array}$} & \\
\hline & $N$ & $\%$ & $N$ & $\%$ & $N$ & $\%$ & $N$ & $\%$ & \\
\hline Total & 5149 & 100.0 & 2035 & 39.5 & 2142 & 41.6 & 972 & 18.9 & \\
\hline 0-4-year-olds & 988 & 19.2 & 431 a & 43.6 & $398 \mathrm{a}, \mathrm{b}$ & 40.3 & $159_{b}$ & 16.1 & \multirow{4}{*}{$28.579(p<0.001)$} \\
\hline 5-9-year-olds & 378 & 7.3 & $165 \mathrm{a}$ & 43.7 & $144 \mathrm{a}$ & 38.1 & $69 a$ & 18.3 & \\
\hline 10-14-year-olds & 531 & 10.3 & $240 \mathrm{a}$ & 45.2 & $200_{b}$ & 37.7 & $91 \mathrm{a}, \mathrm{b}$ & 17.1 & \\
\hline 15-19-year-olds & 3252 & 63.2 & $1199 \mathrm{a}$ & 36.9 & $1400_{b}$ & 43.1 & $653_{\mathrm{b}}$ & 20.1 & \\
\hline
\end{tabular}

Note: excludes four cases with unknown IRSAD classification. Each subscript letter $(a, b)$ denotes a subset of IRSAD Grouped into Low Mid

High categories whose column proportions do not differ significantly from each other at the 0.05 level using the Bonferroni adjustment (i.e., where there are two a's these are not statistically significant, where there is an a and b these are statistically significant).

Road traffic and other land transport was the leading mechanism of injury-related fatalities in areas classified as low IRSAD (38.9\%) and mid IRSAD (40.7\%). In areas classified as high IRSAD, intentional self-harm accounted for the highest proportion of injury-related deaths $(32.4 \%)$. Statistically significant differences $\left(X^{2}=69.05 ; p<0.001\right)$ were found for proportion of injury mechanism by IRSAD for road traffic and other land transport (more likely in low and mid IRSAD deciles), accidental poisoning (high IRSAD), and intentional self-harm (low and mid IRSAD) (Table 8).

When exploring sex differences by injury mechanism, age and IRSAD decile, 15-19year-old males accounted for a significantly higher proportion of drowning-related deaths in low $(96.3 \%$ male), mid $(89.2 \%)$ and high $(90.9 \%)$ IRSAD deciles. Females aged $0-4$ years old accounted for $71.4 \%$ of burn-related deaths in high IRSAD deciles. A higher proportion of males aged 15-19 years of age died from intentional self-harm in low IRSAD deciles ( $72.7 \%$ male) compared to mid (68.5\% male) and high IRSAD deciles (66.1\% male). 
Table 8. Injury-related fatalities by age group and index of relative socio-economic advantage and disadvantage decile (IRSAD), Australia, 2007-08 to 2016-17.

\begin{tabular}{|c|c|c|c|c|c|c|c|c|c|}
\hline \multirow{3}{*}{$\begin{array}{c}\text { Mechanism of } \\
\text { Injury-Related Fatalities }\end{array}$} & \multicolumn{8}{|c|}{ IRSAD Decile } & \multirow{3}{*}{$\begin{array}{c}\mathrm{X}^{2} \\
(p \text { Value })\end{array}$} \\
\hline & \multicolumn{2}{|c|}{ Total } & \multicolumn{2}{|c|}{$\begin{array}{c}\text { Low (Deciles } \\
\text { 1-3) }\end{array}$} & \multicolumn{2}{|c|}{$\begin{array}{c}\text { Mid (Deciles } \\
4-7)\end{array}$} & \multicolumn{2}{|c|}{$\begin{array}{l}\text { High (Deciles } \\
\quad 8-10)\end{array}$} & \\
\hline & $N$ & $\%$ & $N$ & $\%$ & $N$ & $\%$ & $N$ & $\%$ & \\
\hline Total & 5149 & 100.0 & 2035 & 39.5 & 2142 & 41.6 & 972 & 18.9 & - \\
\hline Road traffic and other land transport & 1970 & 38.3 & $791 \mathrm{a}$ & 40.2 & $871 \mathrm{a}$ & 44.2 & $308_{b}$ & 15.6 & \\
\hline $\begin{array}{l}\text { Water transport, air and space transport } \\
\text { and other/unspecified }\end{array}$ & 39 & 0.8 & $8 \mathrm{a}$ & 20.5 & $24_{b}$ & 61.5 & $7 \mathrm{a}, \mathrm{b}$ & 17.9 & \\
\hline Falls & 92 & 1.8 & 29 a & 31.5 & $40 \mathrm{a}$ & 43.5 & $23 \mathrm{a}$ & 25.0 & \\
\hline Exposure to mechanical forces & 125 & 2.4 & $47 \mathrm{a}$ & 37.6 & $56 \mathrm{a}$ & 44.8 & $22 \mathrm{a}$ & 17.6 & \\
\hline Drowning & 418 & 8.1 & $175 \mathrm{a}$ & 41.9 & $171 \mathrm{a}$ & 40.9 & $72 \mathrm{a}$ & 17.2 & \\
\hline $\begin{array}{c}\text { Electrocution, radiation and extreme } \\
\text { temperatures }\end{array}$ & 15 & 0.3 & $5 \mathrm{a}$ & 33.3 & $6 \mathrm{a}$ & 40.0 & $\mathrm{NP}_{\mathrm{a}}$ & NP & 69.052 \\
\hline Burns & 111 & 2.2 & $38 \mathrm{a}$ & 34.2 & $55 \mathrm{a}$ & 49.5 & 18 a & 16.2 & 01) \\
\hline Forces of nature & 35 & 0.7 & $12 \mathrm{a}$ & 34.3 & $16 \mathrm{a}$ & 45.7 & $7 \mathrm{a}$ & 20.0 & \\
\hline Accidental poisoning & 167 & 3.2 & $52 \mathrm{a}$ & 31.1 & $72 \mathrm{a}, \mathrm{b}$ & 43.1 & $43_{b}$ & 25.7 & \\
\hline Accidental exposure to other forces & 39 & 0.8 & $12 \mathrm{a}$ & 30.8 & $12 \mathrm{a}$ & 30.8 & $15_{\mathrm{b}}$ & 38.5 & \\
\hline Intentional self-harm & 1431 & 27.8 & $555 \mathrm{a}$ & 38.8 & $561 \mathrm{a}$ & 39.2 & $315_{b}$ & 22.0 & \\
\hline Assault & 292 & 5.7 & $124 \mathrm{a}$ & 42.5 & $110 \mathrm{a}$ & 37.7 & 58 a & 19.9 & \\
\hline Undetermined intent & 143 & 2.8 & 65 a & 45.5 & $54 \mathrm{a}$ & 37.8 & $24 \mathrm{a}$ & 16.8 & \\
\hline Other accidental threats to breathing & 228 & 4.4 & $100 \mathrm{a}$ & 43.9 & $80 \mathrm{a}$ & 35.1 & 48 a & 21.1 & \\
\hline Other & 44 & 0.9 & $22 \mathrm{a}$ & 50.0 & $14 \mathrm{a}$ & 31.8 & $8 \mathrm{a}$ & 18.2 & \\
\hline
\end{tabular}

Note: excludes four cases with unknown IRSAD classification. NP = Not Presented. Each subscript letter $(a, b)$ denotes a subset of IRSAD Grouped into Low Mid High categories whose column proportions do not differ significantly from each other at the 0.05 level using the Bonferroni adjustment (i.e., where there are two a's these are not statistically significant, where there is an a and $b$ these are statistically significant).

\section{Discussion}

Injury is a leading, yet preventable cause of death among children. This study has explored the impact of determinants of health, namely remoteness of residential location and IRSAD of residential location on injury-related fatalities among 0-19-year-olds in Australia. This study reports the injury-related fatalities of 5153 children aged 0-19 years, with the highest rates occurring among adolescents 15-19 years (22.23/100,000 population). The highest rates of injury-related fatalities being due to the mechanisms of road traffic and other land transport (3.39), intentional self-harm (2.46) and drowning (0.72). Rates of injuryrelated fatality increased as remoteness increased, with six times the risk of an injury-related fatality for children aged 0-19 years in very remote areas of Australia when compared to those residing in major cities. Males and 15-19-year-olds recorded the highest rates of injury-related fatality across all remoteness classifications and age bands, with the highest rate seen among 15-19-year-olds in very remote areas (a rate of 102.33/100,000 people).

Variations in fatal injury risk also exist based on the socio-economic advantage or disadvantage of where children live. While sex did not significantly impact injury-related fatalities when examined by IRSAD decile, significant differences were seen by age band and injury mechanism. Fatal injury risk was most pronounced in low IRSAD areas for very young children (0-4 years of age) and in high IRSAD areas for 15-19-year-olds. Road transport and other land transport injury-related fatalities and intentional self-harm fatalities were significantly more likely in low and mid IRSAD deciles, while accidental poisoning-related fatalities were significantly more likely in high IRSAD deciles. We now focus our discussion on the three leading injury mechanisms identified in the study being road traffic and other land-based transport, intentional self-harm and drowning. We then look to the future with respect to preventative efforts, while also focusing on the opportunity that the new National Injury Prevention Plan provides. 
Road traffic and other land-based transport incidents accounted for the largest number of fatalities ( $n=1970,38 \%)$ across the study period. High rates were seen across all remoteness classifications, with the fatality risk associated with this mechanism six times higher $(R R=5.87$; CI: 2.83-12.18) in very remote areas when compared to major cities. Similarly, road traffic injuries were significantly more likely in areas classified as low $(n=791,40 \%)$ and mid ( $n=871,42 \%$ ) IRSAD deciles. Road surfaces are generally of poorer quality in regional and remote Australia [40], there is a greater diversity of vehicles on the road [41], lower populations see lower investment in vital transport-related infrastructure [42] and higher speeds and driver fatigue all contribute to high fatality rates on regional Australian roads [43]. This, combined with regional dwelling populations often having to travel longer distances by road to seek major services including medical care [44-46], leads to increased exposure and risk of injury and death. Investment in higher quality rural roads which allow for passing and accommodate the wider range of vehicles may be a strategy to reduce injury-related fatalities [43], while upstream, policy approaches, such as investing in more regionally based doctors and specialist services [46] may also be required.

Socio-economic status impacts the mode of transport used [47]. For residents of lowsocio economic areas, the use of lower cost, older vehicles with poorer safety standards may be contributing to an increased risk of death [43]. Strategies to combat this may be policy approaches such as subsidies to improve vehicle quality and investment in improving infant restraint fitting and correct use [48]. Research also indicates that residents of low socio-economic areas have higher exposure to traffic [49] and see lower investment in transport-related infrastructure [50]. Similar to addressing road traffic-related mortality in geographically isolated areas, multi-faceted strategies will be needed to reduce injury risk. For children and adolescents who are too young to drive, such strategies must take a whole community level approach and or target parents and caregivers.

Intentional self-harm was the second leading cause of injury-related mortality among children in Australia across the study period, accounting for $28 \%$ of all deaths. Intentional self-harm recorded the highest fatality rate of any mechanism in very remote areas (16.97 per 100,000 residents), a rate that is eight times ( $R R=8.02$; CI: 4.06-15.84) that of the fatality rate in major cities. Adolescence is a period of high risk for suicide, due to multiple stressors, mood disorders and development phase [51,52]. Though legislation in Australia significantly limits firearm availability and familiarity among potential users, compared to firearm-heavy nations such as the United States [53], increased access to firearms in rural areas may be a contributing factor to increased risk of intentional self-harm-related death in remote areas of Australia [54,55].

Like most other injury mechanisms explored, this study identified that the risk of an intentional self-harm-related fatality was significantly higher for residents of low and mid IRSAD deciles. The published literature has also identified this increased intentional self-harm risk in areas of socio-economic disadvantage [56,57]. Given the impact of broader social factors on risk of intentional self-harm, upstream social and economic approaches that seek to redress socio-economic disadvantage of children and adolescents in Australia are recommended, beyond the provision of mental health services [58].

This study found drowning to be the third leading cause of injury-related fatalities among children in Australia. Like other injury mechanisms, rates increased as remoteness increased, aside from a slightly higher rate in inner regional (1.45 per 100,000 residents) than outer regional (1.41), with a four times $(\mathrm{RR}=4.05$; CI: $0.74-22.22)$ greater risk of drowning in very remote areas than in major cities. Similarly, a higher proportion of drowning occur in areas of low and mid socio-economic status, with just $17.2 \%$ of drowning deaths occurring in high socio-economic areas. This is in keeping with other studies into drowning which have identified significantly higher rates of drowning as rurality increases $[59,60]$ and in low socio-economic areas [61,62].

A range of upstream factors also impact drowning risk, with less pools, seasonal facilities and a lack of instructors impacting ability to learn to swim in regional and remote areas [59], and the limited provision of school-based lessons and the high cost of 
private lessons a barrier for low-socio economic families [63]. Unpatrolled inland waterways used for recreation [60] and higher rates of alcohol consumption combined with aquatic activity [64], are also factors increasing drowning risk in regional and remote areas. Social determinants, such as remoteness and socio-economic disadvantage, are important factors impacting drowning risk and must be considered by drowning prevention practitioners. Very few drowning prevention initiatives targeting regional and remote communities have been evaluated [59], providing meagre evidence to direct limited funding to the most effective strategies.

Greater investment is clearly needed in primary prevention measures to reduce injuryrelated mortality and morbidity in regional and remote Australia and among areas of socio-economic disadvantage [65]. This will require also addressing the determinants of health and taking a wider lens when developing prevention programs, including ensuring programs are piloted in rural areas, engaging with families through co-design [66] and investing in infrastructure in low socio-economic areas [67]. Primary prevention measures must however, go hand in hand with improved tertiary prevention strategies, such as community first aid and cardiopulmonary resuscitation (CPR) [68] and trauma care services $[69,70]$.

The existence of the new National Injury Prevention Strategy 2020-2030 [71], which identifies the impact of determinants of health such as remoteness and socio-economic status in many of its priority populations and priority areas, may serve as a driver to generate policy change and increased investment in addressing groups at increased injury risk due to determinants of health.

Preventing injury-related harm is vital to the nation's addressing many of the child and adolescent health targets outlined in the Sustainable Development Goals [23,24]. More broadly, injury prevention efforts intersect many global agendas such as healthy aging, climate change, water safeguarding, urbanization and corporate social responsibility [24]. As part of the United Nations' Decade of Action to 2030, leveraging the broader impacts of, and intersections with, injury prevention may present opportunities for greater political commitment to tackling this preventable cause of mortality and morbidity. This study has identified opportunities for further research, in particular the need for greater implementation and evaluation of injury prevention interventions targeted at residents of regional and remote and low socio-economic areas of Australia across a range of injury mechanisms. Advocacy to encourage greater investment in injury prevention in these disadvantaged areas will be strengthened by the evidence to support the best return on investment.

\section{Strengths and Limitations}

This study adds to the limited literature exploring the impact of injury related fatality among children aged 0-19 years in Australia by determinants of health, namely remoteness and socio-economic status of residential location at a total population level. The study uses a nationally validated data source and is likely to have consistency and accuracy with respect to the identification of cause of death. Where population data were available, this study uses rates to explore risk of injury-related fatalities per 100,000 residents.

There are, however, some limitations associated with this study. This study explores fatalities only, and further research is needed to explore the full burden of injury-related morbidity. Population data by IRSAD decile are not publicly available in Australia and therefore we were unable to calculate fatality rates by IRSAD. Assumption made regarding population distribution across the all-age population grouped IRSAD deciles holding true for children aged 0-19 years may not be correct. As such, the chi square tests of significance should be interpreted with caution. As remoteness and IRSAD are calculated at the statistical local area level, this limits any individual advantage or disadvantage which may occur within a statistical local area. For example, in an area considered to be low IRSAD, it is possible that there are households which would be considered high within the IRSAD classification. With respect to remoteness, some of the statistical areas 
are quite large, potentially spanning several remoteness classifications, however in this study, they have been assigned to a single remoteness classification.

\section{Conclusions}

This study has explored the impact of determinants of health, namely the geographical remoteness of residence and socio-economic status of residential area on injury-related fatalities among children aged 0-19 years in Australia. This study identified road traffic and other land transport injuries, intentional self-harm and drowning to be the three leading causes of death, with fatality rates increasing as remoteness increased. For most injury mechanisms examined that there was a disproportionate burden among low and middle IRSAD deciles except for intentional self-harm and accidental poisoning related deaths, which were significantly higher in high IRSAD areas. The findings of this study suggest injury prevention strategies for young people in Australia should consider these determinants of health. People residing in regional and remote areas and from low socioeconomic backgrounds already face significant health and lifestyle challenges associated with disadvantage. It is time to invest in these populations to minimize any further preventable loss of life.

Author Contributions: Conceptualization, A.E.P. and R.C.F.; methodology, A.E.P. and R.C.F.; formal analysis, A.E.P. and R.C.F.; data curation, R.C.F.; writing—original draft preparation, A.E.P.; writing - review and editing, A.E.P. and R.C.F.; visualization, A.E.P. All authors have read and agreed to the published version of the manuscript.

Funding: This research received no external funding.

Institutional Review Board Statement: This study was conducted according to the guidelines of the Declaration of Helsinki, and approved by the Human Research Ethics Committee of James Cook University (H6136).

Informed Consent Statement: Informed consent was not able to be obtained as subjects are deceased.

Data Availability Statement: Agreements in place for use of data in this study place restrictions on the public storage of such data. Those interested in gaining access to the data used in this study, should contact the Australian Bureau of Statistics via email: client.services@abs.gov.au.

Conflicts of Interest: The authors declare no conflict of interest.

\section{References}

1. James, S.L.; Castle, C.D.; Dingels, Z.V.; Fox, J.T.; Hamilton, E.B.; Liu, Z.; Roberts, N.L.S.; Sylte, D.O.; Henry, N.J.; LeGrand, K.E.; et al. Global injury morbidity and mortality from 1990 to 2017: Results from the Global Burden of Disease Study 2017. Inj. Prev. 2020, 26 (Suppl. 1), i96-i114. [CrossRef] [PubMed]

2. Franklin, R.C.; Peden, A.E.; Hamilton, E.B.; Bisignano, C.; Castle, C.D.; Dingels, Z.V.; Hay, S.I.; Liu, Z.; Mokdad, A.H.; Roberts, N.L.S.; et al. The burden of unintentional drowning: Global, regional and national estimates of mortality from the Global Burden of Disease 2017 Study. Inj. Prev. 2020. [CrossRef]

3. James, S.L.; Lucchesi, L.R.; Bisignano, C.; Castle, C.D.; Dingels, Z.V.; Fox, J.T.; Hamilton, E.B.; Henry, N.J.; Krohn, K.J.; Liu, Z.; et al. The global burden of falls: Global, regional and national estimates of morbidity and mortality from the Global Burden of Disease Study 2017. Inj. Prev. 2020, 26 (Suppl. 1), i3-i11. [CrossRef] [PubMed]

4. James, S.L.; Lucchesi, L.R.; Bisignano, C.; Castle, C.D.; Dingels, Z.V.; Fox, J.T.; Hamilton, E.B.; Liu, Z.; McCracken, D.; Nixon, M.; et al. Morbidity and mortality from road injuries: Results from the Global Burden of Disease Study 2017. Inj. Prev. 2020, 26 (Suppl. 1), i46-i56. [CrossRef] [PubMed]

5. Braveman, P.; Gottlieb, L. The Social Determinants of Health: It's Time to Consider the Causes of the Causes. Public Health Rep. 2014, 129 (Suppl. 2), 19-31. [CrossRef]

6. Marmot, M.; Friel, S.; Bell, R.; Houweling, T.A.J.; Taylor, S.; Commission on Social Determinants of Health. Closing the gap in a generation: Health equity through action on the social determinants of health. Lancet 2008, 372, 1661-1669. [CrossRef]

7. Laflamme, L. Explaining socio-economic differences in injury risks. Inj. Control Saf. Promot. 2001, 8, 149-153. [CrossRef]

8. Pickett, W.; Molcho, M.; Simpson, K.; Janssen, I.; Kuntsche, E.; Mazur, J.; Harel, Y.; Boyce, W.F. Cross national study of injury and social determinants in adolescents. Inj. Prev. 2005, 11, 213-218. [CrossRef]

9. Cenderadewi, M.; Franklin, R.C.; Devine, S. Socio-Ecological Nature of Drowning in Low-and Middle-Income Countries: A Review to Inform Health Promotion Approaches. Int. J. Aquat. Res. Educ. 2020, 12, 6. [CrossRef]

10. Mitchell, R.J.; Chong, S. Comparison of injury-related hospitalised morbidity and mortality in urban and rural areas in Australia. Rural Remote Health 2010, 10, 1326. 
11. Coben, J.H.; Tiesman, H.M.; Bossarte, R.M.; Furbee, P.M. Rural-Urban Differences in Injury Hospitalizations in the U.S., 2004. Am. J. Prev. Med. 2009, 36, 49-55.

12. Strong, K. Health in Rural and Remote Australia: The First Report of the Australian institute of Health and Welfare on Rural Health; Australian Institute of Health and Welfare: Canberra, Australia, 1998.

13. Ziersch, A.; Baum, F.; Darmawan, I.G.N.; Kavanagh, A.; Bentley, R. Social capital and health in rural and urban communities in South Australia. Aust. N. Z. J. Public Health 2009, 33, 7-16. [CrossRef] [PubMed]

14. Larson, A. Rural health's demographic destiny. Rural Remote Health 2006, 6, 551. [PubMed]

15. Simpson, K.; Janssen, I.; Craig, W.M.; Pickett, W. Multilevel analysis of associations between socioeconomic status and injury among Canadian adolescents. J. Epidemiol. Community Health 2005, 59, 1072-1077. [CrossRef] [PubMed]

16. Birken, C.S.; MacArthur, C. Socioeconomic status and injury risk in children. Paediatr. Child Health 2004, 9, 323-325. [CrossRef]

17. Cubbin, C.; LeClere, F.B.; Smith, G.S. Socioeconomic status and injury mortality: Individual and neighbourhood determinants. J. Epidemiol. Community Health 2000, 54, 517-524. [CrossRef]

18. Cubbin, C.; LeClere, F.B.; Smith, G.S. Socioeconomic status and the occurrence of fatal and nonfatal injury in the United States. Am. J. Public Health 2000, 90, 70-77.

19. Peden, M.M. World Report on Child Injury Prevention_UNICEF; World Health Organization: Geneva, Switzerland, 2008.

20. Peden, A.E.; Franklin, R.C.; Clemens, T. Can child drowning be eradicated? A compelling case for continued investment in prevention. Acta Paediatr. 2020, 0, 1-8. [CrossRef]

21. Khambalia, A.; Joshi, P.; Brussoni, M.; Raina, P.; Morrongiello, B.; MacArthur, C. Risk factors for unintentional injuries due to falls in children aged 0-6 years: A systematic review. Inj. Prev. 2006, 12, 378-381. [CrossRef]

22. Sonkin, B.; Edwards, P.; Roberts, I.; Green, J. Walking, Cycling and Transport Safety: An Analysis of Child Road Deaths. J. R. Soc. Med. 2006, 99, 402-405. [CrossRef]

23. United Nations. Sustainable Development Goals Knowledge Platform—Sustainable Development Goal 3 2020. Available online: https: / / sustainabledevelopment.un.org/sdg3 (accessed on 7 July 2020).

24. Ma, T.; Peden, A.E.; Peden, M.; Hyder, A.; Jagnoor, J.; Duan, L.; Brown, J.; Passmore, J.; Clapham, K.; Tian, M.; et al. Out of the silos: Embedding injury prevention into the Sustainable Development Goals. Inj. Prev. 2020. [CrossRef] [PubMed]

25. Harvey, A. Injury Prevention and the Attainment of Child and Adolescent Health. Bull. World Health Organ. 2009, 87, 390-394. [CrossRef] [PubMed]

26. Roberts, I.; Power, C. Does the decline in child injury mortality vary by social class? A comparison of class specific mortality in 1981 and 1991. BMJ 1996, 313, 784-786. [CrossRef] [PubMed]

27. Australian Bureau of Statistics. Underlying causes of death (Australia) 2018; Australian Bureau of Statistics: Canberra, Australia, 2019.

28. Australian Bureau of Statistics. Main Structure and Greater Capital City Statistical Areas. In 1270.0.55.001-Australian Statistical Geography Standard (ASGS); Australian Bureau of Statistics: Canberra, Australia, 2016; Volume 1. Available online: https:/ / www.abs.gov.au/ausstats/abs@.nsf/Lookup/by\%20Subject/1270.0.55.001 \{\}July\%202016 \{\}Main\%20Features \{\}Statistical\%20Area\%20Level\%202\%20(SA2) \{\}10014 (accessed on 7 July 2020).

29. National Centre for Classification in Health. The International Statistical Classification of Diseases and Related Health Problems, 10th ed.; Australian modification (ICD-10-AM); National Centre for Classification in Health: Sydney, Australia, 1998.

30. Australian Bureau of Statistics, Australian Standard Geographical Classification (ASGC). Statistical Geography; Australian Bureau of Statistics: Canberra, Australia, 2006; Volume 1.

31. Australian Bureau of Statistics. 2033.0.55.001-Census of Population and Housing: Socio-Economic Indexes for Areas (SEIFA), Australia, 2011; Australian Bureau of Statistics: Canberra, Australia, 2013. Available online: http://www.abs.gov.au/ausstats/abs@.nsf/ Lookup/2033.0.55.001main+features100042011 (accessed on 7 July 2020).

32. Australian Bureau of Statistics. 2033.0.55.001-Census of Population and Housing: Socio-Economic Indexes for Areas (SEIFA), Australia, 2016; Australian Bureau of Statistics: Canberra, Australia, 2018. Available online: https://www.abs.gov.au/ausstats/abs@.nsf/ Lookup/by\%20Subject/2033.0.55.001 \{\}2016 \{\}Main\%20Features \{\}IRSAD \{\}20 (accessed on 7 July 2020).

33. Australian Bureau of Statistics. Socio-Economic Indexes for Areas; Australian Bureau of Statistics: Canberra, Australia, 2018. Available online: https://www.abs.gov.au/websitedbs/censushome.nsf/home/seifa (accessed on 5 November 2020).

34. Australian Bureau of Statistics. Population-Australia; Australian Bureau of Statistics: Canberra, Australia, 2020.

35. Australian Bureau of Statistics. 2011 Census QuickStats; Australian Bureau of Statistics: Canberra, Australia, 2013. Available online: http: / / www.censusdata.abs.gov.au/census_services/getproduct/census/2011/quickstat/0?opendocument\&navpos=220 (accessed on 5 November 2020).

36. Australian Bureau of Statistics. 2016 Census QuickStats; Australian Government; Australian Bureau of Statistics: Canberra, Australia, 2017.

37. MEDCALC. Medcalc_Relative Risk Calculator; 2017; Available online: https://www.medcalc.org/calc/relative_risk.php (accessed on 5 November 2020).

38. IBM Corporation. IBM SPSS Statistics for Windows Version 25; IBM Corp: Armonk, NY, USA, 2010.

39. Keppel, G. Design and Analysis: A Researcher's Handbook, 3rd ed.; Prentice Hall: Englewood Cliffs, NJ, USA, 1991.

40. Peiris, S.; Berecki-Gisolf, J.; Chen, B.K.; Fildes, B. Road Trauma in Regional and Remote Australia and New Zealand in Preparedness for ADAS Technologies and Autonomous Vehicles. Sustainability 2020, 12, 4347. [CrossRef] 
41. Franklin, R.C.; King, J.C.; Riggs, M. A Systematic Review of Large Agriculture Vehicles Use and Crash Incidents on Public Roads. J. Agromed. 2020, 25, 14-27. [CrossRef]

42. McKenzie, F. Population Decline in Non-Metropolitan Australia: Impacts and Policy Implications. Urban Policy Res. 1994, 12, 253-263. [CrossRef]

43. Wundersitz, L.; Palamara, P.; Brameld, K.; Raftery, S.; Thompson, J.; Govorko, M.; Watts, M. Regional and Remote Road Safety: A National View; Austroads: Canberra, Australia, 2019.

44. McGrail, M.R.; Humphreys, J.S. The index of rural access: An innovative integrated approach for measuring primary care access. BMC Health Serv. Res. 2009, 9, 124. [CrossRef]

45. Phillips, A. Rural, Regional, and Remote Health: Indicators of Health Status and Determinants of Health; Australian Institute of Health and Welfare: Canberra, Australia, 2008.

46. Armstrong, B.K.; Ba, J.A.G.; Leeder, S.R.; Rubin, G.L.; Russell, L.M. Challenges in health and health care for Australia. Med. J. Aust. 2007, 187, 485-489. [CrossRef]

47. Rachele, J.N.; Kavanagh, A.M.; Badland, H.; Giles-Corti, B.; Washington, S.; Turrell, G. Associations between individual socioeconomic position, neighbourhood disadvantage and transport mode: Baseline results from the HABITAT multilevel study. J. Epidemiol. Community Health 2015, 69, 1217-1223. [CrossRef]

48. Johns, M.; Lennon, A.; Haworth, N. Child Car Restraints:Mandating Type and Seating Row According to Age with Positive Effect in Regional City in Queensland, Australia. Transp. Res. Rec. 2012, 2281, 51-58. [CrossRef]

49. Rachele, J.N.; Learnihan, V.; Badland, H.M.; Mavoa, S.; Turrell, G.; Giles-Corti, B. Neighbourhood socioeconomic and transport disadvantage: The potential to reduce social inequities in health through transport. J. Transp. Health 2017, 7, 256-263. [CrossRef]

50. Wiesel, I.; Liu, F.; Buckle, C. Locational disadvantage and the spatial distribution of government expenditure on urban infrastructure and services in metropolitan Sydney (1988-2015). Geogr. Res. 2018, 56, 285-297. [CrossRef]

51. Rutter, P.A.; Behrendt, A.E. Adolescent suicide risk: Four psychosocial factors. Adolescence 2004, 39, 295. [PubMed]

52. Brent, D.A.; Baugher, M.; Bridge, J.; Chen, T.; Chiappetta, L. Age- and Sex-Related Risk Factors for Adolescent Suicide. J. Am. Acad. Child Adolesc. Psychiatry 1999, 38, 1497-1505. [CrossRef]

53. Zalsman, G.; Hawton, K.; Wasserman, D.; van Heeringen, K.; Arensman, E.; Sarchiapone, M.; Carli, V.; Höschl, C.; Barzilay, R.; Balazs, J.; et al. Suicide prevention strategies revisited: 10-year systematic review. Lancet Psychiatry 2016, 3, 646-659. [CrossRef]

54. Snowdon, J.; Harris, L. Firearms suicides in Australia. Med. J. Aust. 1990, 156, 79-83. [CrossRef]

55. Dudley, M.; Kelk, N.; Florio, T.; Waters, B.; Howard, J.; Taylor, D. Coroners' Records of Rural and Non-Rural Cases of Youth Suicide in New South Wales. Aust. N. Z. J. Psychiatry 1998, 32, 242-251. [CrossRef]

56. Cairns, J.-M.; Graham, E.; Bambra, C. Area-level socioeconomic disadvantage and suicidal behaviour in Europe: A systematic review. Soc. Sci. Med. 2017, 192, 102-111. [CrossRef]

57. Law, B.M.F.; Shek, D.T.L. A 6-year Longitudinal Study of Self-harm and Suicidal Behaviors among Chinese Adolescents in Hong Kong. J. Pediatric Adolesc. Gynecol. 2016, 29 (Suppl. 1), S38-S48. [CrossRef]

58. Taylor, R.; Page, A.; Morrell, S.; Carter, G.; Harrison, J.E.; Carter, G. Socio-economic differentials in mental disorders and suicide attempts in Australia. Br. J Psychiatry 2004, 185, 486-493. [CrossRef]

59. Taylor, D.; Peden, A.E.; Franklin, R.C. Next steps for drowning prevention in rural and remote Australia: A systematic review of the literature. Aust. J. Rural Health. Available online: https://onlinelibrary.wiley.com/doi/abs/10.1111/ajr.12674 (accessed on 20 November 2020). [CrossRef]

60. Peden, A.E.; Willcox-Pidgeon, S.M.; Scarr, J.P.; Franklin, R.C. Comparing rivers to lakes: Implications for drowning prevention. Aust. J. Rural Health. Available online: https://onlinelibrary.wiley.com/doi/abs/10.1111/ajr.12679 (accessed on 24 November 2020). [CrossRef]

61. Peden, A.E.; Franklin, R.C.; Pearn, J.H. The prevention of child drowning: The causal factors and social determinants impacting fatalities in portable pools. Health Promot. J. Aust. 2020, 31, 184-191. [CrossRef] [PubMed]

62. Peden, A.E.; Barnsley, P.D.; Queiroga, A.C. The association between school holidays and unintentional fatal drowning among children and adolescents aged 5-17 years. J. Paediatr. Child Health 2018, 55, 533-538. [CrossRef] [PubMed]

63. Willcox-Pidgeon, S.M.; Peden, A.E.; Scarr, J. Exploring children's participation in commercial swimming lessons through the social determinants of health. Health Promot. J. Aust. 2020, 1-10. [CrossRef] [PubMed]

64. Peden, A.E.; Franklin, R.C.; Leggat, P.A. Breathalysing and surveying river users in Australia to understand alcohol consumption and attitudes toward drowning risk. BMC Public Health 2018, 18, 1393. [CrossRef]

65. Ingram, G.; Kessides, C. Infrastructure for development. J. Financ. Dev. 1994, 31, 18.

66. Winschiers-Theophilus, H.; Winschiers-Goagoses, N.; Kasper Rodil, E.B.; Zaman, T.; Gereon Koch Kapuire, R.K. Moving away from Erindi-roukambe: Transferability of a rural community-based co-design. In Proceedings of the 12th International Conference on Social Implications of Computers in Developing Countries, Montego Bay, Jamaica, 19-22 May 2013.

67. Pawson, H.; Hulse, K.; Cheshire, L. Addressing Concentrations of Disadvantage in Urban Australia; Australian Housing and Urban Research Institute: Melbourne, Australia, 2015.

68. Peden, A.E.; Franklin, R.C.; Leggat, P.A. Cardiopulmonary resuscitation and first-aid training of river users in Australia: A strategy for reducing drowning. Health Promot. J. Aust. 2019, 30, 258-262. [CrossRef]

69. Cameron, P.; Dziukas, L.; Hadj, A.; Clark, P.; Hooper, S. Major Trauma in Australia: A Regional Analysis. J. Trauma Acute Care Surg. 1995, 39, 545-552. [CrossRef] 
70. Fatovich, D.M.; Jacobs, I.G. The Relationship between Remoteness and Trauma Deaths in Western Australia. J. Trauma 2009, 67, 910-914. [CrossRef]

71. Australian Government Department of Health. National Injury Prevention Strategy 2020-2030 (Draft for Consultation); Australian Government Department of Health: Canberra, Australia, 2020. 